OPEN ACCESS

Edited by:

Pedro Gamito,

Universidade Lusófona, Portugal

Reviewed by:

Jorge Oliveira,

Universidade Lusófona, Portugal

Franco Delogu,

Lawrence Technological University,

United States

*Correspondence:

Sara Ventura

sara.ventura@uv.es

Specialty section:

This article was submitted to

Cognitive Science,

a section of the journal

Frontiers in Psychology

Received: 17 June 2019 Accepted: 23 October 2019

Published: 14 November 2019

Citation:

Ventura S, Brivio E, Riva G and Baños RM (2019) Immersive Versus Non-immersive Experience: Exploring the Feasibility of Memory Assessment Through $360^{\circ}$ Technology.

Front. Psychol. 10:2509.

doi: 10.3389/fpsyg.2019.02509

\section{Immersive Versus Non-immersive Experience: Exploring the Feasibility of Memory Assessment Through $360^{\circ}$ Technology}

\author{
Sara Ventura ${ }^{1 *}$, Eleonora Brivio ${ }^{2}$, Giuseppe Riva ${ }^{2,3}$ and Rosa M. Baños ${ }^{1,4}$ \\ ${ }^{1}$ Department of Personality, Assessment and Psychological Treatments, University of Valencia, Valencia, Spain, ${ }^{2}$ Department \\ of Psychology, Centro Studi e Ricerche di Psicologia della Comunicazione, Università Cattolica del Sacro Cuore, Milan, \\ Italy, ${ }^{3}$ Applied Technology for Neuro-Psychology Laboratory, Auxologico Institute, Milan, Italy, ${ }^{4}$ CIBERObn Ciber \\ Physiopathology of Obesity and Nutrition, Madrid, Spain
}

Episodic memory is essential to effectively perform a number of daily activities, as it enables individuals to consciously recall experiences within their spatial and temporal environments. Virtual Reality (VR) serves as an efficacious instrument to assess cognitive functions like attention and memory. Previous studies have adopted computer-simulated VR to assess memory, which realized greater benefits compared to traditional procedures (paper and pencil). One of the most recent trends of immersive VR experiences is the $360^{\circ}$ technology. In order to evaluate its capabilities, this study aims to compare memory performance through two tasks: immersive task and non-immersive task. These tasks differ based on the participant's view of the $360^{\circ}$ picture: (1) head-mounted display (HMD) for immersive task and (2) tablet for non-immersive task. This study seeks to compare how memory is facilitated in both the $360^{\circ}$ immersive picture as well as the non-immersive $360^{\circ}$ picture. A repeated measure design was carried out in a sample of 42 participants, randomized into two groups of 21. Group 1 first observed Picture A (immersive) followed by Picture B (non-immersive) while Group 2 began with Picture B and then looked at Picture A. Each $360^{\circ}$ picture contains specific items with some items appearing in both. Memory evaluation is assessed immediately after the exposure (recall task), then again after a 10-min delay (recognition task). Results reveal that Group 1, which began with the immersive task, demonstrated stronger memory performance in the long term as compared to Group 2, which began with the non-immersive task. Preliminary data ultimately supports the efficacy of the $360^{\circ}$ technology in evaluating cognitive function.

Keywords: panorama technology, $360^{\circ}$ camera, memory assessment, episodic memory, case-comparison

\section{INTRODUCTION}

In the last few decades, Virtual Reality (VR) has shown to be an efficacious instrument in assessing cognitive functions such as attention, memory, and executive functions. VR is defined as an advanced form of human-computer interfaces that allow the user to interact with and be immersed in a virtual environment that reflects reality (Schultheis and Rizzo, 2001). 
Researchers have demonstrated that VR-based intervention methods have several important benefits as compared to traditional methods. Traditional methods consist of a set of predefined stimuli delivered in a controlled environment via paper-and-pencil or computer systems (Wilson et al., 1989; Negut et al., 2016); however, they have only a moderate level of ecological validity in predicting real-world performance (Alvarez and Emory, 2006; Parsons, 2015). To overcome this limitation, researchers have adopted VR approaches to develop neuropsychological programs that evaluate participants in situations as close as possible to real life (Parsons and Rizzo, 2008; Parsons, 2015; Gamito et al., 2017; Parsons and Barnett, 2017). Specifically, a number of VR platforms have been developed to study and train memory abilities (Castelnuovo et al., 2003; Armstrong et al., 2013; Gamito et al., 2016; Lee et al., 2018). These virtual environments allow users to simulate daily activities such as purchasing products from a shopping list or recalling a route from one point to another within a virtual city (Dores et al., 2012; Parsons and Barnett, 2017). Although results have been encouraging, highlighting the advantages of using VR for cognitive assessment (Faria et al., 2016; Gamito et al., 2018), the development of these virtual environments requires a high economic investment, both in software and hardware requirements.

One recent trend in technology field is the $360^{\circ}$ technology (Huang et al., 2017). The $360^{\circ}$ camera can record the environment in all directions, allowing users to look up and down, left and right, as he or she can do in real-life situations. More so, it is affordable and does not require any specific technical skills for basic use (Parsons, 2015; Serino et al., 2017). Because of its versatility, the $360^{\circ}$ technology has been used in various fields like education (McKenzie et al., 2019), immersive journalism (Schutte and Stilinović, 2017), and advertising (Habig, 2016). This paper presents a case study of the feasibility of alternative approaches to create VR content for memory assessment. Specifically, instead of creating graphics-based VR scenarios (Slater and Sanchez-Vives, 2016), the $360^{\circ}$ technology was used to record a familiar environment before playing it to participants on a head-mounted display (HMD).

The $360^{\circ}$ videos can be experienced through immersive and non-immersive media (Negro-Cousa et al., 2019). Immersive and non-immersive media vary based upon the participant's point-of-view and the experience produced during use. Through immersive $360^{\circ}$ technology, participants can view the full panorama with the HMD VR support, creating a high sense of presence and immersion, as if they are essentially inside the environment. Through non-immersive $360^{\circ}$ environments, participants can view the $360^{\circ}$ panorama content by moving or rotating the device in which the content is played, such as a PC, smartphone, or tablet (Repetto et al., 2018). In this view, participants are only external observers. The difference between immersive and non-immersive environments can be better clarified through the concept of spatial presence.

Abbreviations: VR, Virtual reality; HMD, Head-mounted display; RBMT, Rivermead behavioral memory test; MFE-Q, Failure of everyday questionnaire; SSQ, Simulator sickness questionnaire.
Spatial presence is defined as "the sense of being in an environment" (Kober et al., 2012). Immersive $360^{\circ}$ environments allow participants to feel as though they are inside the environment while non-immersive environments only allow participants to see the contents based on how the device in use - PC, smartphone, or tablet - is held and moved.

Robertson et al. (2016) adopted an immersive condition for memory evaluation and investigated how visual images are represented by the brain. The authors found that as participant views a panorama picture, the images processed in his or her brain are merged to create the perceptual experience of a coherent continuous panorama. This likely occurs because immersive $360^{\circ}$ picture or video elicits the sense of realism and the feeling of being submerged into the environment (Serino and Repetto, 2018). Subsequently, this study aims to investigate the efficacy of $360^{\circ}$ panorama technology in strengthening memory function. Specifically, we hypothesized that participants in the $360^{\circ}$ immersive condition could better perform in memory tasks than those in the $360^{\circ}$ non-immersive condition.

The study was approved by The Ethics Committee of Valencia University (Spain), with registration number: H1543407702114.

\section{MATERIALS AND METHODS}

\section{Participants}

A total of 42 participants were recruited from students and faculty at the University of Valencia. The sample size has been determined by $G^{*}$ Power 3 software (Faul et al., 2007) and a total of 21 participants per group has been estimated, taking into account an alpha error of 0.05 , a statistical power of 0.80 , and the effect size was found in a previous study (Negro-Cousa et al., 2019).

The inclusion criteria were as follows: (1) ages 18 years and older; (2) proficiency in Spanish; and (3) without physical limitations, especially in the neck or back, that could prevent free body movements. All participants were volunteers and signed the informed consent document before participation in the study, in accordance with the Declaration of Helsinki.

\section{$360^{\circ}$ Pictures and Apparatus}

The $360^{\circ} \mathrm{VR}$ environments were composed of two $360^{\circ}$ pictures of bedrooms containing different sets of common household items. Bedroom A (Figure 1A) featured the following target objects: backpack, painting, trousers, shoes, and bottle; Bedroom B (Figure 1B) has the following target objects: glass, T-shirt, slippers, luggage, and portrait. The concepts depicted in each picture according to the objects placed within it are familiar. Familiarity has been shown to have an important effect on various memory- and cognitive-processing tasks. According to Alario and Ferrand (1999), familiarity was rated as an important predictor of picture-naming latencies. Essentially, the naming time is faster when a participant is more familiar with a concept. For example, the bottle in Bedroom $A$ was replaced with a vase in Bedroom $B$, or a backpack was replaced with a luggage. Additionally, both pictures have five complementary objects: bed, table, personal computer, mirror, and wardrobe (Sauzéon et al., 2012; 

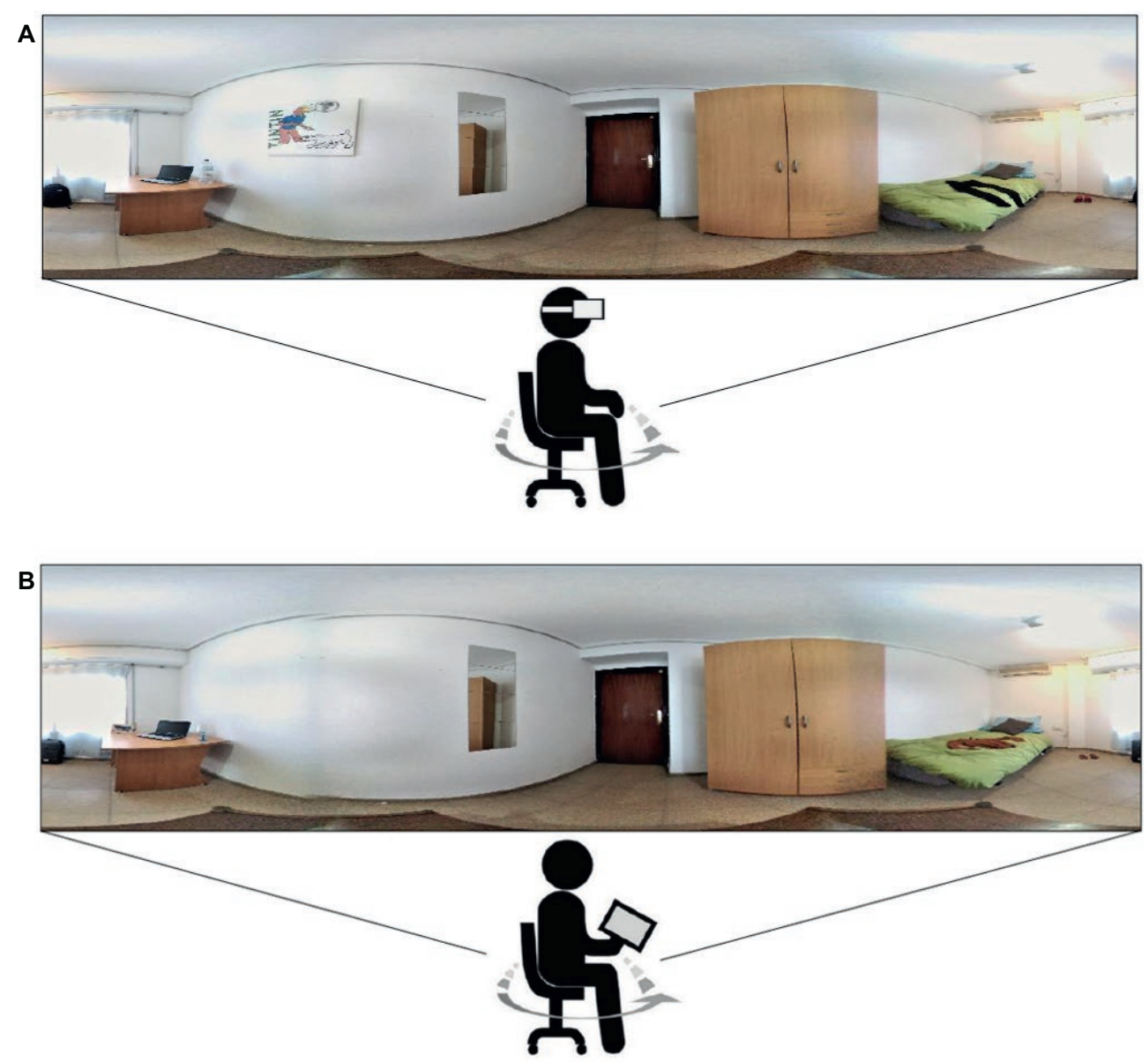

FIGURE 1 | Study task. (A) Participants look at the $360^{\circ}$ panorama picture through VR headset (immersive condition); (B) participants look at $360^{\circ}$ panorama picture through tablet (non-immersive condition).

Sauzeon et al., 2016; Negro-Cousa et al., 2019). To generate the $360^{\circ}$ pictures, the LG360-105 camera and the linked LG360 viewer software for the edit were used. The non-immersive $360^{\circ}$ picture was displayed on a Samsung Galaxy Tab A $25.65 \mathrm{~cm}$ $\left(10.1^{\prime \prime}\right)$ Tablet, and the immersive $360^{\circ}$ picture was displayed on an iPhone 6 via a VR head-mounted display (HMD).

\section{Procedure}

Consenting participants in the study were randomly assigned to one of two conditions using the Random Allocation Software 2.0 (Saghaei, 2004). A within-subject counterbalanced design was used: Group 1 first viewed Picture A (immersive) followed by Picture B (non-immersive), and Group 2 first viewed Picture B (non-immersive), then Picture A (immersive) (Figure 1). The counterbalanced design was adopted to avoid the complications connected to a repeated presentation of similar stimuli, and to avoid the primary effect of memory. In this study, the sample was recruited from a non-clinical population with no declared memory deficit, and it was hypothesized that the counterbalanced design could emphasize the difference between the immersive and non-immersive conditions. For participants without memory impairments, it could be easy to remember a list of objects regardless the type of the condition; however, the counterbalanced design was used to minimize the carryover effect (Sayette et al., 2010) as participants perform in more than one condition (immersive and non-immersive or non-immersive and immersive) where the first picture allows for better recollection of the second.

The study took place at the Department of Psychology at the University of Valencia. Participants came to the laboratory, signed the written informed consent, and filled out the sociodemographic questionnaire. Participants were then invited to sit on a swivel chair to ensure the greatest comfort while viewing the $360^{\circ}$ picture - through either the HMD for the immersive picture or on the tablet for the non-immersive picture. For the immersive condition, participants looked at a neutral picture in order to focus the image as well as to adjust and calibrate the HMD before displaying the experimental picture. The experiment is composed of three phases: (1) encoding phase, (2) recall phase, and (3) recognition phase (Table 1). During the encoding phase, participants first viewed Picture A or B, depending on the condition they were assigned, for $50 \mathrm{~s}$, then completed the free recall task. Then they viewed the second picture followed by completion of the free recall task again. A 
TABLE 1 | Counterbalanced design.

\begin{tabular}{|c|c|}
\hline Group 1 & Group 2 \\
\hline 1. View bedroom A (Figure 1A) & 1. View bedroom B (Figure 1B) \\
\hline 2. Free recall task & 2. Free recall task \\
\hline 3. View bedroom B (Figure 1B) & 3. View bedroom A (Figure 1A) \\
\hline 4. Free recall task & 4. Free recall task \\
\hline 5. Questionnaires & 5. Questionnaires \\
\hline $\begin{array}{l}\text { 6. Recognition task of bedroom A } \\
\text { (Figure 1A) }\end{array}$ & $\begin{array}{l}\text { 6. Recognition task of bedroom B } \\
\text { (Figure 1B) }\end{array}$ \\
\hline
\end{tabular}

10-min delay was implemented before participants completed the recognition task, where they utilized a written list to identify as many items as they could from the first picture viewed. This procedure (Sauzéon et al., 2012) allowed for best observing the effect of immersive and non-immersive setups for memory ability.

\section{Measures}

\section{Sociodemographic Questionnaire}

An ad hoc questionnaire was created to collect information about each participant's age, gender, highest education level attained, and physical abilities. This questionnaire was administered as part of the screening process for the study.

\section{Memory Failure of Everyday Questionnaire}

This is a 28-item questionnaire that measures memory forgetfulness in daily life, rated on a $0-2$ scale $(0=$ never, $1=$ sometimes, 2 = many times) (Carrasco et al., 2012). The scale includes three subscales: (1) activities memory, (2) recognition, and (3) communication monitoring. This questionnaire was administered to document possible memory deficits. Higher scores indicate low memory ability. The Spanish adaptation of the scale was used with an adequate internal consistency for the total score $(\alpha=0.87)$ (Montejo et al., 2014).

\section{Simulator Sickness Questionnaire}

This a 16-item questionnaire that measures the level of discomfort perceived during the $360^{\circ}$ immersive condition (Kennedy et al., 1993). The scale includes two subscales: (1) nausea and (2) ocular-motor sickness. It is an adaptation to Spanish from the original scale, reviewed by a bilingual English-Spanish researcher.

\section{Computer Experience}

The questionnaire is composed of five questions that investigate the usability and experience with technology, rated on a scale of $1-5$ (from 1 = very bad to $5=$ very good). This questionnaire was administered to evaluate the participants' usability and familiarity with technology, in particular with the $360^{\circ}$ apparatus. Higher scores indicate greater usage of new technologies. It is an adaptation to Spanish from the ad hoc original scale (Schuemie, 2003), reviewed by a bilingual English-Spanish researcher.

\section{Memory Task}

The test is an adaptation of a previous work by Sauzeon et al. (2016) and measures the ability to remember the objects from the pictures viewed during the experiment. It is composed of two sub-tasks:
1. Free recall tasks where participants are asked to recall as many items as they can of the pictures they are shown on the immersive and non-immersive technologies. The free recall task was administered immediately after looking at the $360^{\circ} \mathrm{VR}$ environments. For each task, there are two scores: (1) target score, referring to the number of the target objects recalled for each picture and (2) common score, referring to the number of the recalled objects present in both pictures. Both scores are rated on a scale of $0-5$ ( $0=$ no item remembered, $5=$ all items remembered $)$.

2. Recognition task where participants have to recognize, from a written list, as many items as they can from the first pictures they viewed. The list consists of 10 varying objects presented in the two rooms and 5 common objects, for a total of 15 items. In this case, there are five interfering objects for both groups (five objects belong to other room) and 10 correct items. The recognition task was administered after a 10-min delay from the exposure. It is an adaptation to Spanish from the original scale (Negro-Cousa et al., 2019), reviewed by a bilingual English-Spanish researcher.

\section{RESULTS}

Statistical analyses were performed using the SPSS v.24.

\section{Sample Characteristics}

The sample was composed of 17 females (40.5\%) and 25 males $(59.5 \%)$. The most represented age group was $18-24$ years ( $n=26 ; 61.9 \%)$, followed by $25-30$ years $(n=10 ; 23.8 \%)$, and $34-55$ years $(N=6 ; 14.3 \%)$. The level of education was undergraduate $(n=8 ; 19.1 \%)$, bachelor's degree $(n=21 ; 50 \%)$, master's degree $(n=7 ; 16.7 \%)$, and Doctor of Philosophy $(n=6 ; 14.3 \%)$. Analyses of Failure of Everyday Questionnaire (MFE-Q) indicated a total score of $12.82(\mathrm{SD}=6.09)$; specifically for each factor: (1) memory activity $M=4.99(\mathrm{SD}=2.67)$; (2) recognition $M=1.08$ ( $\mathrm{SD}=1.44$ ), and (3) memory communication $M=5.80(\mathrm{SD}=3.31)$. Since the maximum score for the questionnaire is $56(2 \times 28$ item $)$, the average score of 12.82 indicated that the sample did not manifest particular memory deficit in daily life activities. The Simulator Sickness Questionnaire (SSQ) showed a moderate score of sickness for the immersive condition: nausea $M=9.82$ $(\mathrm{SD}=2.57)$ and oculomotor $M=10.02(\mathrm{SD}=3.34)$. Moreover, participants had a good but not excellent experience with $360^{\circ}$ technologies and VR in general $M=12.24(\mathrm{SD}=1.90)$.

\section{Memory Task}

After counterbalancing the groups, two paired $t$-tests were carried out to investigate whether the $360^{\circ}$ immersive picture would facilitate free memory recollection in comparison to a non-immersive $360^{\circ}$ condition. Results revealed no significant difference between conditions for both "target recall task" $t(41)=-0.79, p=0.429 ; 95 \%$ CI $(-0.218,0.504)$ and "common recall task" $t(41)=-0.11, p=0.906 ; 95 \%$ CI $(-0.380,0.428)$. The descriptive statistics are shown in Table 2. 
TABLE 2 | Descriptive statistics of recall task.

\begin{tabular}{lllll}
\hline & N & Min. & Max. & M (SD) \\
\hline Recall_Target (immersive) & 42 & 1 & 5 & $3.95(1.05)$ \\
Recall_Target (non-immersive) & 42 & 1 & 5 & $3.80(1.27)$ \\
Recall_Common (immersive) & 42 & 1 & 5 & $3.95(1.03)$ \\
Recall_Common (non-immersive) & 42 & 1 & 5 & $3.92(1.04)$ \\
\hline
\end{tabular}

TABLE 3 | Descriptive statistics of recognition task.

\begin{tabular}{llccc}
\hline & N & Min. & Max. & M (SD) \\
\hline Recall_Target (immersive) & 21 & 1 & 5 & $\mathbf{4 . 1 0 ( 0 . 8 3 )}$ \\
Recall_Target (non-immersive) & 21 & 1 & 5 & $\mathbf{3 . 3 8}(\mathbf{1 . 3 2})$ \\
Recall_Common (immersive) & 21 & 1 & 5 & $4.38(0.80)$ \\
Recall_Common (non-immersive) & 21 & 1 & 5 & $4.43(0.92)$ \\
\hline
\end{tabular}

Values in bold are statistically different between conditions.

Furthermore, independent $t$-test was carried out to evaluate the difference between conditions for the "recognition task." Results showed a significant difference in "target recognition task" for the immersive condition $t(40)=2.09, p=0.42 ; 95 \%$ CI $(0.026$, 1.403). However, there was no significant difference between groups on "common recognition task" $t(40)=-0.18, p=0.860 ; 95 \%$ CI $(0.589,0.493)$. The descriptive statistics are shown in Table 3.

Two paired $t$-tests for each group were adopted to investigate the difference between immersive and non-immersive conditions to better evaluate the carryover effect. Group 1 (order immersive and non-immersive) showed a significant difference in "common recall task" but not for "target recall task" while Group 2 (order non-immersive and immersive) demonstrated a significant difference for the "target recall task" but not for "common recall task" (Table 4).

Finally, moderation analyses showed that the specific subscale of MFE-Q did not moderate the effect of condition on memory tasks, both target and common recognition. Specifically, (1) recognition target: memory ability $F(1,42)=0.123, p=0.727$, memory recognition $F(1,42)=1.029, p=0.317$ and memory communication $F(1,42)=0.088, p=0.768$; (2) recognition common: memory ability $F(1,42)=0.478, p=0.493$, memory recognition $F(1,42)=0.354, p=0.556$ and memory communication $F(1,42)=0.087, p=0.770$.

\section{DISCUSSION}

The $360^{\circ}$ camera is an innovative technology in the field of immersive VR. Recently, researchers have investigated the validity of $360^{\circ}$ technology to assess episodic memory (Serino et al., 2017; Negro-Cousa et al., 2019). In this study, the general objective was to explore the feasibility of the $360^{\circ}$ technology to assess memory ability. We compared $360^{\circ}$ immersive and non-immersive setups in the memory task. Specifically, we hypothesized that participants in the $360^{\circ}$ immersive condition could better perform than the $360^{\circ}$ non-immersive condition in memory tasks.

This study confirmed the hypothesis that the immersive $360^{\circ}$ panorama is more efficient in regard to memory ability than the non-immersive condition. Results showed no significant difference between immersive and non-immersive conditions for the "free recall task," both in target and common tasks, which can be explained by the lack of any specific memory disorder among participants. All participants showed proficient memory ability in daily life activities, as evaluated by the $M F E-Q$. Further analyses also revealed that memory ability did not moderate the effect of condition on both target and common recognition tasks; however, the results in the "recognition task" were statistically significant for the target items. The recognition task administered after a 10 -min delay from the exposure to the $360^{\circ}$ picture can explain how the immersive exposure aids long-term memory encoding more than non-immersive exposure. The significance occurs only in the target task of the recognition test, namely for the recollection of the specific objects of the single room A or B - but not for the common objects (Figure 1). The difference can be explained by the notions that participants may find it easier to recall objects presented twice than just a single exposure. Repeated exposures to the same stimuli increase the probability of recollection (Baddeley, 2012).

Finally, through the analysis of the independent Groups 1 and 2, results showed that Group 2, which encoded the $360^{\circ}$ picture in the "non-immersive and immersive" order had significantly better recall scores in the second free recall task (after the presentation of $360^{\circ}$ pictures through the immersive technology) rather than in the first free recall task (after the presentation of $360^{\circ}$ pictures through non-immersive technology). These results support the idea that a more immersive condition was able to strengthen the memory ability for the specific objects, likely due to the sense of spatial presence elicited during the experience, as suggested by previous research (Serino and Repetto, 2018). The significance for the specific items is not present for the Group 1 order "immersive and non-immersive." The realism provided by the $360^{\circ}$ immersive environment and the relative sense of spatial presence - defined as "the sense of being there," in a virtual or physical environment (Riva and Mantovani, 2012) - seem to play a role in strengthening the memory trace, which the non-immersive condition does not support. It can be hypothesized that the sense of presence vanishes when participants switch from an immersive to a non-immersive environment, while the sense of presence is strongest when participants switch from non-immersive to immersive environment. Makowski et al. (2017) and Schutte and Stilinovic (2017) found that the sense of presence and the emotions experienced during the projection of a movie increased the capacity to recall specific frames watched during the experiment. In particular, the impact of emotions on memory recall was mediated by presence. In this study, the significance of remembered common objects occurred in Group 1 ("immersive and non-immersive") but not in Group 2 ("non-immersive and immersive"). Even when objects are presented twice - in either condition - participants recalled them better only when they switched from immersive to non-immersive condition. One possible explanation is that the immersive condition - an innovative instrument for most participants - distracts the participants from what they had 
TABLE 4 | Performance of participants in memory task for each condition.

\begin{tabular}{|c|c|c|c|c|c|c|}
\hline & & Immersive: $M$ (SD) & Non-immersive: $M$ (SD) & $t$ & df & $p$ \\
\hline \multirow[t]{3}{*}{ Group 1: immersive and non-immersive } & Target & $4.14(1.017)$ & $4.48(1.062)$ & -1.503 & 20 & 0.149 \\
\hline & Common & $4.19(1.207)$ & $3.62(0.814)$ & 2.168 & 20 & 0.042 \\
\hline & Total score & $8.33(1.238)$ & $8.09(1.220)$ & 0.794 & 20 & 0.437 \\
\hline \multirow[t]{3}{*}{ Group 2: non-immersive and immersive } & Target & $3.76(1.117)$ & $3.14(1.315)$ & -2.540 & 20 & 0.020 \\
\hline & Common & $3.71(1.167)$ & $4.24(0.889)$ & 2.057 & 20 & 0.053 \\
\hline & Total score & $7.476(2.040)$ & $7.38(1.774)$ & -0.336 & 20 & 0.741 \\
\hline
\end{tabular}

seen some seconds before through the headset (non-immersive condition). In the current study, familiarity with technology appears to play an important role. Most participants are accustomed to using non-immersive contents on their devices. An immersive experience could induce the sense of "awe" to participants, which could distract them from the research task (Chirico et al., 2017).

\section{LIMITATIONS AND CONCLUSION}

Two limitations were noteworthy from this study: (1) the sample size and (2) the independent control group. As the current study was only a preliminary research to test the feasibility of the immersive $360^{\circ}$ technology for memory assessment, participants with no memory deficit were recruited, and the counterbalanced design emerged to be the most suitable strategy for indicating the differences between immersive and non-immersive conditions.

Future works should introduce measures for sense of presence to evaluate how it can moderate memory change. Larger sample sizes and a Randomized Control Trial design should also be implemented to better verify how the $360^{\circ}$ immersive environment can be effectively used in memory assessment, as suggested by this study. Lastly, possible future works could be directed to populations with memory impairments to test if $360^{\circ}$ technology could be an efficient rehabilitation tool to strengthen memory ability, as preliminary results of this study confirmed.

\section{DATA AVAILABILITY STATEMENT}

The datasets generated for this study are available on request to the corresponding author.

\section{REFERENCES}

Alario, F. X., and Ferrand, L. (1999). A set of 400 pictures standardized for French: Norms for name agreement, image agreement, familiarity, visual complexity, image variability, and age of acquisition. Behav. Res. Methods Instrum. Comput. 31, 531-552. doi: 10.3758/BF03200732

Alvarez, J. A., and Emory, E. (2006). Executive function and the frontal lobes: a meta-analytic review. Neuropsychol. Rev. 16, 17-42. doi: 10.1007/s11065-006-9002-x

Armstrong, C. M., Reger, G. M., Edwards, J., Rizzo, A. A., Courtney, C. G., and Parsons, T. D. (2013). Validity of the virtual reality stroop task (VRST)

\section{ETHICS STATEMENT}

The studies involving human participants were reviewed and approved by Ethics Committee of Valencia University (Spain). Registration number: H1543407702114. The patients/participants provided their written informed consent to participate in this study.

\section{AUTHOR CONTRIBUTIONS}

SV made substantial contribution to the conceptualization and design of the experiment, formal analyses, collection of the data and drafting the manuscript. EB made substantial contribution to the conceptualization and design of the experiment and in revising the manuscript. GR and RB made substantial contribution in revising the manuscript critically for important intellectual content. All authors provided final approval of the version to be published and agreed to be accountable for all aspects of the work as well as in ensuring that questions related to the accuracy or integrity of any part of the work are appropriately investigated and resolved.

\section{FUNDING}

This study was funded by the Excellence Research Program PROMETEO (PROMETEO/2018/110/Conselleria d'Educació, Investigació, Cultura I Esport, Generalitat Valenciana).

\section{ACKNOWLEDGMENTS}

This work was supported by Santiago Grisolía program - Generalitat Valenciana 2017 (Spain) and CIBEROBN - ISCIII (Spain).

in active duty military. J. Clin. Exp. Neuropsychol. 35, 113-123. doi: $10.1080 / 13803395.2012 .740002$

Baddeley, A. (2012). Working memory: theories, models, and controversies. Annu. Rev. Psychol. 63, 1-29. doi: 10.1146/annurev-psych-120710-100422

Carrasco, P. M., Peña, M. M., and Sueiro, M. J. (2012). The memory failures of everyday questionnaire (MFE): internal consistency and reliability. Span. J. Psychol. 15, 768-776. doi: 10.5209/rev_SJOP.2012.v15.n2.38888

Castelnuovo, G., Priore, C. L., Liccione, D., and Cioffi, G. (2003). Virtual reality based tools for the rehabilitation of cognitive and executive functions: the V-STORE. PsychNology J. 1, 310-325. 
Chirico, A., Cipresso, P., Yaden, D. B., Biassoni, F., Riva, G., and Gaggioli, A. (2017). Effectiveness of immersive videos in inducing awe: an experimental study. Sci. Rep. 7:1218. doi: 10.1038/s41598-017-01242-0

Dores, A. R., Carvalho, I. P., Barbosa, F., Almeida, I., Guerreiro, S., Oliveira, B., et al. (2012). "Computer-assisted rehabilitation program - virtual reality (CARPVR): a program for cognitive rehabilitation of executive dysfunction" in Virtual and Networked Organizations, Emergent Technologies and Tools, ViNOrg 2011. Communications in Computer and Information Science, Vol. 248. eds. G. D. Putnik and M. M. Cruz-Cunha (Berlin, Heidelberg: Springer).

Faria, A. L., Andrade, A., Soares, L., and Badia, S. B. (2016). Benefits of virtual reality based cognitive rehabilitation through simulated activities of daily living: a randomized controlled trial with stroke patients. J. Neuroeng. Rehabil. 13:96. doi: 10.1186/s12984-016-0204-Z

Faul, F., Erdfelder, E., Lang, A. G., and Buchner, A. (2007). G* power 3: a flexible statistical power analysis program for the social, behavioral, and biomedical sciences. Behav. Res. Methods 39, 175-191. doi: 10.3758/BF03193146

Gamito, P., Morais, D., Oliveira, J., Ferreira Lopes, P., Picareli, L. F., Matias, M., et al. (2016). Systemic Lisbon battery: normative data for memory and attention assessments. JMIR Rehabil. Assist. Technol. 3:e5. doi: 10.2196/rehab.4155

Gamito, P., Oliveira, J., Coelho, C., Morais, D., Lopes, P., Pacheco, J., et al. (2017). Cognitive training on stroke patients via virtual reality-based serious games. Disabil. Rehabil. 39, 385-388. doi: 10.3109/09638288.2014.934925

Gamito, P., Oliveira, J., Morais, D., Coelho, C., Santos, N., Alves, C., et al. (2018). Cognitive stimulation of elderly individuals with instrumental virtual reality-based activities of daily life: pre-post treatment study. Cyberpsychol. Behav. Soc. Netw. 22, 69-75. doi: 10.1089/cyber.2017.0679

Habig, J. (2016). Is 360 video worth it. Available at: https://think.storage.googleapis. com/docs/360-video-advertising.pdf (Accessed February 19, 2017).

Huang, J., Chen, Z., Ceylan, D., and Jin, H. (2017 IEEE Virtual Reality (VR), Los Angeles, CA). 6-DOF VR videos with a single 360-camera, 37-44.

Kennedy, R. S., Lane, N. E., Berbaum, K. S., and Lilienthal, M. G. (1993). Simulator sickness questionnaire: an enhanced method for quantifying simulator sickness. Int. J. Aviat. Psychol. 3, 203-220. doi: 10.1207/ s15327108ijap0303_3

Kober, S. E., Kurzmann, J., and Neuper, C. (2012). Cortical correlate of spatial presence in $2 \mathrm{D}$ and $3 \mathrm{D}$ interactive virtual reality: an EEG study. Int. J. Psychophysiol. 83, 365-374. doi: 10.1016/j.ijpsycho.2011.12.003

Lee, G. J., Bang, H. J., Lee, K. M., Kong, H. H., Seo, H. S., Oh, M., et al. (2018). A comparison of the effects between 2 computerized cognitive training programs, Bettercog and COMCOG, on elderly patients with MCI and mild dementia: a single-blind randomized controlled study. Medicine 97:e13007. doi: 10.1097/MD.0000000000013007

Makowski, D., Sperduti, M., Nicolas, S., and Piolino, P. (2017). "Being there" and remembering it: presence improves memory encoding. Conscious. Cogn. 53, 194-202. doi: 10.1016/j.concog.2017.06.015

McKenzie, S., Rough, J., Spence, A., and Patterson, N. (2019). Virtually there: the potential, process and problems of using 360 video in the classroom. IISIT 16, 211-219. doi: 10.28945/4318

Montejo, P., Montenegro, M., Sueiro, M. J., and Huertas, E. (2014). Cuestionario de Fallos de Memoria de la Vida Cotidiana (MFE). Análisis de factores con población española. Ann. Psychol. 30, 320-328. doi: 10.6018/analesps. 30.1.131401

Negro-Cousa, E., Brivio, E., Serino, S., Heboyan, V., Riva, G., and De Leo, G. (2019). New Frontiers for cognitive assessment: an exploratory study of the potentiality of $360^{\circ}$ technologies for memory evaluation. Cyberpsychol. Behav. Soc. Netw. 22, 76-81. doi: 10.1089/cyber.2017.0720

Negut, A., Matu, S. A., Sava, F. A., and David, D. (2016). Virtual reality measures in neuropsychological assessment: a meta-analytic review. Clin. Neuropsychol. 30, 165-184. doi: 10.1080/13854046.2016.1144793

Parsons, T. D., and Rizzo, A. A. (2008). Initial validation of a virtual environment for assessment of memory functioning: virtual reality cognitive performance assessmenttest. Cyberpsychol. Behav. 11, 17-25. doi: 10.1089/ cpb.2007.9934

Parsons, T. D. (2015). Virtual reality for enhanced ecological validity and experimental control in the clinical, affective and social neurosciences. Front. Hum. Neurosci. 9:660. doi: 10.3389/fnhum.2015.00660

Parsons, T. D., and Barnett, M. (2017). Validity of a newly developed measure of memory: feasibility study of the virtual environment grocery store. $J$. Alzheimer's Dis. 59, 1227-1235. doi: 10.3233/JAD-170295

Repetto, C., Germagnoli, S., Triberti, S., and Riva, G. (2018). "Learning into the wild: a protocol for the use of $360^{\circ}$ video for foreign language learning" in International symposium on pervasive computing paradigms for mental health (Cham: Springer), 56-63.

Robertson, C. E., Hermann, K. L., Mynick, A., Kravitz, D. J., and Kanwisher, N. (2016). Neural representations integrate the current field of view with the remembered 360 panorama in scene-selective cortex. Curr. Biol. 26, 2463-2468. doi: 10.1016/j.cub.2016.07.002

Riva, G., and Mantovani, F. (2012). From the body to the tools and back: a general framework for presence in mediated interactions. Interact. Comput. 24, 203-210. doi: 10.1016/j.intcom.2012.04.007

Saghaei, M. (2004). Random allocation software for parallel group randomized trials. BMC Med. Res. Methodol. 4:26. doi: 10.1186/1471-2288-4-26

Sayette, M. A., Griffin, K. M., and Sayers, W. M. (2010). Counterbalancing in smoking cue research: a critical analysis. Nicotine Tob. Res. 12, 1068-1079. doi: $10.1093 /$ ntr/ntq159

Sauzéon, H., Pala, P. A., Larrue, F., Wallet, G., Déjos, M., Zheng, X., et al. (2012). The use of virtual reality for episodic memory assessment: effects of active navigation. Exp. Psychol. 59, 99-108. doi: 10.1027/1618-3169/a000131

Sauzeon, H., N'kaoua, B., Arvind Pala, P., Taillade, M., and Guitton, P. (2016). Age and active navigation effects on episodic memory: a virtual reality study. Br. J. Psychol. 107, 72-94. doi: 10.1111/bjop.12123

Schultheis, M. T., and Rizzo, A. A. (2001). The application of virtual reality technology in rehabilitation. Rehabil. Psychol. 46:296. doi: 10.1037/ 0090-5550.46.3.296

Schuemie, M. J. (2003). Human-computer interaction and presence in virtual reality exposure therapy. dissertation $/ \mathrm{PhD}$ thesis. Holland: Bibliotheek Technische Universiteit.

Schutte, N. S., and Stilinović, E. J. (2017). Facilitating empathy through virtual reality. Motiv. Emot. 41, 708-712. doi: 10.1007/s11031-017-9641-7

Serino, S., Baglio, F., Rossetto, F., Realdon, O., Cipresso, P., Parsons, T. D., et al. (2017). Picture interpretation test (PIT) 360: an innovative measure of executive functions. Sci. Rep. 7:16000. doi: 10.1038/s41598-017-16121-x

Serino, S., and Repetto, C. (2018). New trends in episodic memory assessment: immersive $360^{\circ}$ ecological videos. Front. Psychol. 9:1878. doi: 10.3389/ fpsyg.2018.01878

Slater, M., and Sanchez-Vives, M. V. (2016). Enhancing our lives with immersive virtual reality. Front. Robot. AI 3:74. doi: 10.3389/frobt.2016.00074

Wilson, B., Cockburn, J., Baddeley, A., and Hiorns, R. (1989). The development and validation of a test battery for detecting and monitoring everyday memory problems. J. Clin. Exp. Neuropsychol. 11, 855-870. doi: 10.1080/ 01688638908400940

Conflict of Interest: The authors declare that the research was conducted in the absence of any commercial or financial relationships that could be construed as a potential conflict of interest.

Copyright (C) 2019 Ventura, Brivio, Riva and Baños. This is an open-access article distributed under the terms of the Creative Commons Attribution License (CC BY). The use, distribution or reproduction in other forums is permitted, provided the original author(s) and the copyright owner(s) are credited and that the original publication in this journal is cited, in accordance with accepted academic practice. No use, distribution or reproduction is permitted which does not comply with these terms. 